\title{
SPATIAL DISTRIBUTION OF PHLEBOTOMINAE IN PUERTO IGUAZÚ-MISIONES, ARGENTINA-BRAZIL-PARAGUAY BORDER AREA
}

María Soledad SANTINI(1,4), Ignacio Tomas GOULD(1,4), Mariana Manteca ACOSTA(2,4), Pablo BERROZPE(1,4), Soraya Alejandra ACARDI(3,4,6), María Soledad FERNÁNDEZ(1,4,6), Andrea GÓMEZ(5) \& Oscar Daniel SALOMON(2,4,6)

\begin{abstract}
SUMMARY
The first Argentinian autochthonous human case of visceral leishmaniasis (VL) was confirmed in Posadas (Misiones) in 2006. Since then, the disease has increased its incidence and geographical distribution. In the 2006-2012 period, 107 human cases were detected (11 deaths). The presence of Lutzomyia longipalpis was detected in peridomiciles in Puerto Iguazú urban area in 2010; some of these findings were associated with households where cases of canine VL had already been reported. The objective of this study was to ascertain the abundance and spatial distribution of $L u$. longipalpis in Puerto Iguazú City, on the Argentina-Brazil-Paraguay border. Lu. longipalpis proved to be exclusively urban and was found in $31 \%$ of the households sampled $(\mathrm{n}=53)$, 67\% of which belonged to areas of low abundance, $20 \%$ to areas of moderate abundance and $13 \%$ to areas of high abundance. Nyssomyia whitmani was the only species found both in urban and peri-urban environments, and Migonemyia migonei was registered only on the outskirts of the city. Due to the fact that Puerto Iguazú is considered to be at moderate risk at the moment, it is necessary to intensify human and canine case controls, as well as take integrated prevention and control measures regarding the environment, vectors and reservoirs on the Argentina-Brazil-Paraguay border area.
\end{abstract}

KEYWORDS: Phlebotominae fauna; Leishmaniasis; Argentina-Brazil-Paraguay.

\section{INTRODUCTION}

In Argentina, urban visceral leishmaniasis (VL) is an emerging parasitosis; the first human case was registered in 2006 and since then its incidence and geographical distribution ${ }^{20,23}$ have increased. The etiological agent in the region is Leishmania infantum (syn. chagasi); the most frequent vector is Lutzomyia longipalpis, and the main reservoir in urban areas is the domestic dog Canis familiaris ${ }^{8,11}$.

VL presents an annual world incidence estimated at approximately 500,000 cases and mortality of 59,000 ${ }^{26}$. Argentina, like other Latin American countries, has an average mortality rate of around $8 \%{ }^{9}$, which can attain over $90 \%$ of cases of symptomatic infections, especially among children, if untreated ${ }^{13}$.

The presence of $\mathrm{Lu}$. longipalpis was recorded in the city of Corpus, southwest region of Misiones province, in 2000. Due to the recording of LV cases in Paraguay and Brazil, a system of vector vigilance was organized on the border area. This resulted in findings of the VL agent vector in Clorinda, Formosa in $2004^{17}$.

The first case in Argentina was announced in May 2006 in Posadas
City, Misiones ${ }^{20}$. A total of 107 human cases have been detected since then, and 11 deaths reported in several provinces, none of them in Puerto Iguazú City (GOULD et al. ${ }^{9}$ ). Subsequent findings have shown dispersion of the vector $\mathrm{Lu}$. longipalpis towards the south ${ }^{23,24}$, along with cases of canine VL in the provinces of Misiones, Corrientes, Entre Ríos and Formosa ${ }^{23}$. Canine and human cases have also been detected in the province of Santiago del Estero, but Migonemyia migonei, a species which has also been proposed as a link between the wild zoonotic cycle in rural areas and the domestic cutaneous leishmaniasis (CL) ${ }^{19}$, has been implicated as putative vector ${ }^{22}$.

In a study conducted in Puerto Iguazú City in May 2010, the presence of $\mathrm{Lu}$. longipalpis was detected in the urban area; some of the findings were associated with households where cases of canine VL had been reported $^{23}$. In previous samplings conducted on the outskirts of the city, in rural areas and in the intersections of primary-secondary vegetation, the predominant species were Nyssomyia whitmani and $\mathrm{Mg}$. migonei, both of which have been implicated in the spread of CL in several transmission scenarios ${ }^{6,21}$.

The aim of this study was to ascertain the spatial distribution of $L u$. longipalpis abundance in Puerto Iguazú City, Argentina-Paraguay-Brazil

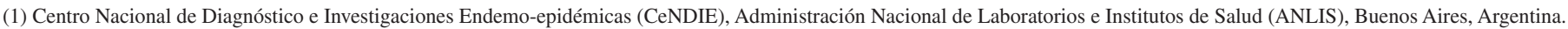

(2) Instituto Nacional de Medicina Tropical (INMeT), Puerto Iguazú, Misiones, Argentina.

(3) Laboratorio de Biología Molecular Aplicada, Facultad de Ciencias Exactas, Químicas y Naturales, Universidad Nacional de Misiones.

(4) Red de Investigación de Leishmaniasis Argentina (REDILA).

(5) Fundación Mundo Sano.

(6) Consejo Nacional de Investigaciones Científicas y Técnicas (CONICET).

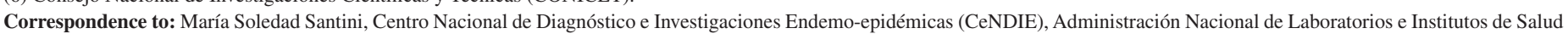
(ANLIS), Buenos Aires, Argentina. Av. Paseo Colón 568, 1063 Buenos Aires, Argentina. Fax: 54114331 2536. E-mail: mariasoledadsantini@gmail.com 


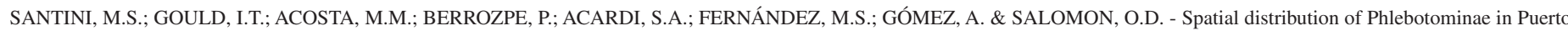
Iguazú-Misiones, Argentina-Brazil-Paraguay border area. Rev. Inst. Med. Trop. Sao Paulo, 55(4): 239-43, 2013.

border area after the first cases of canine VL were registered, in order to develop and standardize effective prevention and control strategies.

\section{MATERIALS AND METHODS}

Area of study: This study was carried out in Puerto Iguazú City (Iguazú department, Misiones province, Argentina (253' S, $5435^{\prime} \mathrm{W}$ ). This city belongs to the phytogeographic region of the Parana forest ${ }^{1}$, which is shared by Argentina, Paraguay and Brazil; the Paraná and Iguazú rivers determine the borders between Argentina and the two neighboring countries. Puerto Iguazú receives over one million tourists a year, and has a stable population of 82,227 inhabitants $^{10}$.

Entomological Sampling: CDC light traps, used for the sampling of Phlebotominae in peridomestic environments, operated from approximately $5 \mathrm{pm}$ to 9 am, except in some households where they had to be removed for logistic reasons around noon. The traps were positioned $1.5 \mathrm{~m}$ above ground for two consecutive rainless nights. In order to sample the entire urban area, the city was divided into $400 \mathrm{~m}^{2}$ patches; one household was selected within each patch using "the worst scenario" criterion (most prone peridomestic households to contain Phlebotominae) $)^{2,4}$. "The worst scenario" is a functional definition to denote a site within the study patch with greater probability of containing Phlebotominae due to habitat conditions and which is therefore of greater biological significance than the geometric center. "The worst scenarios" are distinguished by the presence of thick vegetation which provides shadow, humidity and detritus; soil rich in organic material and access to blood ingestion without the interference of external light.

In order to minimize climatic change which could cause a variance in the capture of vectors, sampling was conducted on four consecutive days (September $24^{\text {th }}-27^{\text {th }}, 2011$ ).

All phlebotomine sandflies were dried and preserved prior to processing. The specimens were cleared with lacto-phenol and identified according to GALATI (2003) under a microscope (40X). Evandromyia cortelezzii and $E v$. sallesi females cannot be distinguished by their external morphology, which is why the specimens collected are included within the Ev. cortelezzii-sallesi complex.

Given that every peridomicile was sampled on two consecutive nights, relative abundance of vectors was calculated from number of specimens collected per trap/night.

Abundance of $\mathrm{Lu}$. longipalpis was classified using operative criteria, as has also been done in other urban areas ${ }^{5}$, as follows: none, with no Lu. longipalpis; low, ranging from 1-29 specimens; moderate, ranging from 30-59 specimens; and high, over 60 specimens.

The geographic coordinates of all the sites sampled were registered with the Global Positioning System. Some of the peridomiciles (between five and 12 per sampling night, according to daily logistic access possibilities) were registered for maximum and minimum temperature levels and relative humidity values.

In order to study how temperature and humidity variations affect the abundance of vectors in the households sampled, variance analysis of the following variables: "total phlebotominae abundance", "minimum temperature", "maximum temperature", "minimum relative humidity", and "maximum relative humidity" was performed. Normality and homoscedasticity assumptions were verified and logarithmic transformation was applied when necessary. The analysis considered only peridomiciles in which sandflies were found and for which the climate variable data were available, taking those with $p$ values under 0.05 as significant results.

\section{RESULTS}

A total of 1,256 Phlebotominae specimens belonging to eight species: Ny. whitmani (67.5\%), Lu. longipalpis (27\%), Mg. migonei (4\%), Pintomyia pessoai (0.7\%), Brumptomyia sp (0.5\%), Ev. cortelezziisallesi $(0.2 \%)$, Psathyromyia shannoni and Micropygomyia quinquefer $(<0.1 \%)$ were captured (capture effort: 97 traps/night) (Table 1). At least one sand fly was captured in $33 \%$ of the households sampled. Of the different species implicated in CL transmission, the presence of $N y$. whitmani was registered in $21 \%$ of the households; that of $\mathrm{Mg}$. migonei in $6.5 \%$ and that of the Ev. cortelezzii-sallesi complex in $5.6 \%$.

\section{Table 1}

Phlebotominae fauna in Puerto Iguazú: number of sand fly per species (male/female), captured in Puerto Iguazú-Misiones, Argentina; September $24^{\text {th }}$ to $27^{\text {th }}, 2011$

\begin{tabular}{lccccc}
\hline Species & Male & Female & $\begin{array}{c}\text { Both } \\
\text { sexes }\end{array}$ & $\%$ & $\begin{array}{c}\text { Male/ } \\
\text { female ratio }\end{array}$ \\
\hline Ny. whitmani & 489 & 361 & 850 & 67.6 & $1.35: 1.0$ \\
Lu. longipalpis & 286 & 50 & 336 & 26.7 & $5.72: 1.0$ \\
Mg. migonei & 16 & 35 & 51 & 4.06 & $0.46: 1.0$ \\
Pi. pessoai & 9 & 0 & 9 & 0.72 & - \\
Brumptomyia sp & 6 & 0 & 6 & 0.48 & - \\
Ev. cortelezzii-sallesi & 0 & 3 & 3 & 0.24 & - \\
Pa. shannoni & 1 & 0 & 1 & 0.08 & - \\
Mi. quinquefer & 1 & 0 & 1 & 0.08 & - \\
\hline Total & $\mathbf{8 0 8}$ & $\mathbf{4 4 9}$ & $\mathbf{1 2 5 7}$ & $\mathbf{1 0 0 . 0}$ & $\mathbf{1 . 8 0 : 1 . 0}$ \\
\hline
\end{tabular}

Lutzomyia longipalpis was found in $31 \%$ of the households sampled $(n=53), 67 \%$ of which belonged to areas of low abundance, $20 \%$ to those of moderate abundance and $13 \%$ to those of high abundance of the species.

The male:female ratio for the three most abundant species is as follows: Ny. whitmani 1.35:1; Lu. longipalpis 5.72:1, and Mg. migonei $0.45: 1$.

A differential spatial distribution was found for the most abundant species: Ny. whitmani was the only species found both in urban and peri-urban households, $\mathrm{Lu}$. longipalpis proved to be exclusively urban, and $\mathrm{Mg}$. migone $i$ was registered only on the outskirts of the city (Fig. 1). The distribution of the less abundant species was limited to households near to the forest.

Joint analysis results for the abundance of sand fly species and 


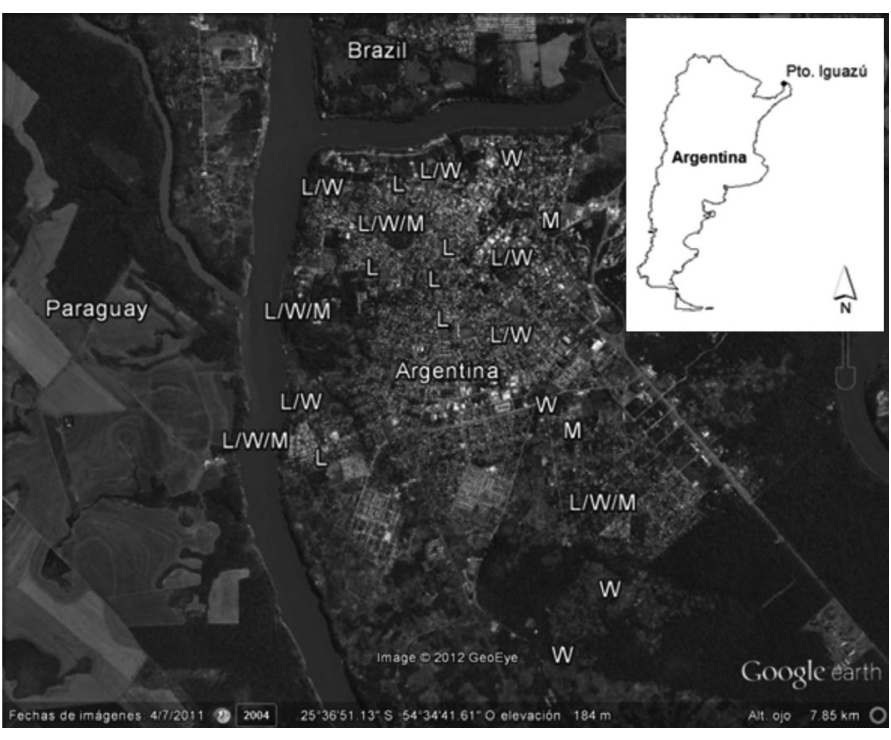

Fig. 1 - Distribution of Ny. whitmani (W), Lu. longipalpis (L) and Mg. migonei (M) in the city of Puerto Iguazú, Misiones Province, Argentina, November $24^{\text {th }}$ to $27^{\text {th }}, 2011$. Images taken from Google Earth, version 4.0.2416 (beta). http://earth.google.es.

climatic variables presented differences in the total abundance of Phlebotominae captured on the consecutive days $\left(\mathrm{F}_{2,8}=5.08 ; p=0.0376\right)$. The day with the highest number of sand flies captured presented the lowest minimum temperature and the highest minimum relative humidity. Records of maximum temperature and maximum relative humidity showed no differences on sampling days (Table 2). The second day was not included in the analysis due to the fact that no sand fly was collected in the households where climatic variables were measured (minimum and maximum temperature, and minimum relative humidity and maximum relative humidity).

\section{DISCUSSION}

This study describes the distribution of the dominant species of the sand fly community, particularly Lu. longipalpis, the main vector of the VL agent of America, in Puerto Iguazú City, in the light of the significance of the area for public health. As the 2005 samplings did not register the presence of this sand fly in the urban area ${ }^{21}$, nor was any wild environment then found, the present study demonstrates the species "successful" colonization of some sectors of the city. Although the major proportion of sampled households showed moderate abundance, it is noteworthy that the minimum temperatures registered on those days were lower than the optimum estimated temperature threshold for the species in the region, i.e., $23{ }^{\circ} \mathrm{C}^{16}$. However, in view of the occurrence and dispersion of the VL agent vector under these weather conditions, its presence in the border area, the presence and unhindered passage of dogs with canine VL on the Argentina-Brazil-Paraguay borders ${ }^{23}$, it is to be supposed that the city of Puerto Iguazú is at epidemiological risk.

Regarding the influence of temperature and relative humidity on the sand fly abundance, even though the peridomiciles sampled for these indicators were not numerous, the preliminary findings obtained show that on the sampling days the vector abundance was reduced by low relative humidity and favored by higher values. As regards to the minimum temperatures registered, the statistical differences found between sampling days may not be of biological relevance since the maximum temperatures registered exceeded the threshold value proposed for the region $\left(23^{\circ} \mathrm{C}\right)^{16}$. These results suggest that on consecutive sampling days when there are no thermal variations of biological relevance, relative minimum humidity would by itself affect vector abundance and would acquire greater importance. These findings should be cross-referenced with seasonal samplings in order to analyze the effect of climatic variation (both between and within seasons) on the abundance of dominant species in the community, particularly on the main or putative vectors of VL $(\mathrm{Lu}$. longipalpis and $\mathrm{Mg}$. migonei) and CL ( $\mathrm{Ny}$. whitmani and $\mathrm{Mg}$. migonei) agents. The analysis presented relating to the abundance of sandflies with humidity and temperature is limited by the number of collections and determinations of climatic variables in the peridomicile with captures, for each of the nights. But the results, preliminary, were interesting because they allow the inference that possibly, on consecutive days within the same station where the temperature is not a limiting factor, the relative humidity is a variable climate of greater relevance than the last.

As in other Argentinian cities studied ${ }^{5}$, the distribution of $L u$. longipalpis has proved to be spatially heterogeneous, as shown by the main vector prediction model of WOOLHOUSE et al. $(1997)^{25}$, and micro scale spatial heterogeneous data for other VL urban areas in America ${ }^{5}$, where a similarity in the proportion of VL vectors in positive households in cities registering an established colonization of approximately $31 \%$ has also been found. The sex ratio showed a greater proportion of $\mathrm{Lu}$. longipalpis males in CDC light traps, as it is frequently mentioned ${ }^{12}$.

Table 2

Variance analysis for the abundance of vectors: variance analysis for the abundance of vectors and climatic variables measured between sampling days. Total sand fly abundance (Total abundance), average minimum temperature ( $\operatorname{minT}$ ), average maximum temperature (maxT), minimum relative humidity (minRH), and maximum relative humidity $(\mathrm{maxRH})$, measured in peridomestic households included in the variance analysis (Days 1, 3 and 4); n: number of peridomiciles included in the analysis. Averages are followed by standard deviations. Different letters indicate significant differences between days for each variance analysis conducted; ns: nosignificant differences

\begin{tabular}{llccccc}
\hline Day & $\mathrm{n}$ & Total abundance & $\operatorname{minT}$ & $\operatorname{maxT}$ & $\operatorname{minRH}$ & maxRH \\
\hline 1 & 3 & $7.7 ; 4.5 \mathrm{ab}$ & $13.3 ; 0.6 \mathrm{a}$ & $29.0 ; 2.0$ & $42.7 ; 4.0 \mathrm{~b}$ & $98.3 ; 1.2$ \\
3 & 6 & $109.8 ; 109.4 \mathrm{~b}$ & $13.7 ; 1.4 \mathrm{a}$ & $30.2 ; 1.8$ & $43.7 ; 6.7 \mathrm{~b}$ & $95.5: 4.2$ \\
4 & 2 & $3.0 ; 1.4 \mathrm{a}$ & $16.5 ; 0.7 \mathrm{~b}$ & $31.5 ; 2.1$ & $27.0 ; 1.4 \mathrm{a}$ & $96.0 ; 4.2$ \\
\hline$p$ value & 0.03 & 0.03 & $\mathrm{~ns}$ & 0.02 \\
\hline
\end{tabular}


SANTINI, M.S.; GOULD, I.T.; ACOSTA, M.M.; BERROZPE, P.; ACARDI, S.A.; FERNÁNDEZ, M.S.; GÓMEZ, A. \& SALOMON, O.D. - Spatial distribution of Phlebotominae in Puerto Iguazú-Misiones, Argentina-Brazil-Paraguay border area. Rev. Inst. Med. Trop. Sao Paulo, 55(4): 239-43, 2013.

In this study, the spatial distribution of $\mathrm{Mg}$. migonei was found to be limited to the outskirts of the city. Previous studies show that this species is usually found in primary vegetation and to a lesser degree in secondary vegetation, but can also be found both in domestic and peridomestic environments ${ }^{14}$. Studies in Santiago del Estero, which only found specimens of $\mathrm{Mg}$. migonei, along with cases of canine and human VL, proposed this species as a possible vector for L. infantum (syn. chagasi). Soon afterwards, the species natural infection with this protozoan was demonstrated in Pernambuco, Brazil ${ }^{3}$. Therefore, in view of the lack of studies to corroborate these findings and knowing the importance that the reservoirs have in the transmission of many parasites, $\mathrm{Mg}$. migonei, given that it is a zoophilic species, could be seen to constitute the nexus between the zoonotic and anthropozoonotic cycles of VL, in the same way as it was assumed to be with $\mathrm{CL}^{19}$, and $\mathrm{Lu}$. longipalpis was concluded to be the species responsible for maintaining the cycle of L. infantum in urban environments (Fig. 2).

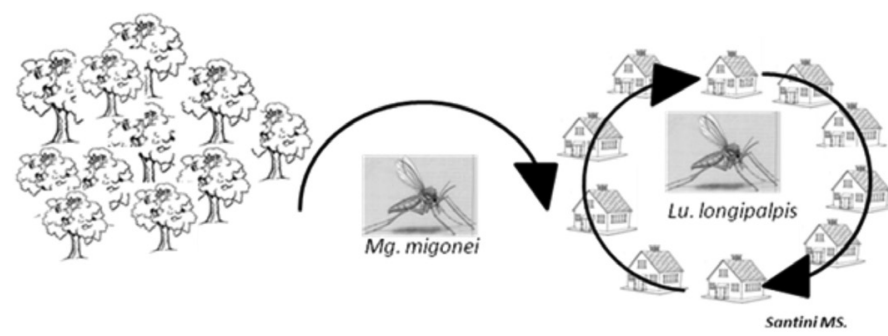

Fig. 2 - Route of transmission of L. infantum: possible route of transmission of Leishmania infantum from wild environments to urban environments. $M g$. migonei would be the species responsible for entering the parasite $L$. infantum into the city, and Lu. longipalpis the species responsible for its transmission in the urban environment.

On the other hand, the most abundant species found in the Puerto Iguazú urban environment was $N y$. whitmani, considered to be the main CL agent vector in the northern area of the Paraná forest, near the capture sectors mentioned in this study ${ }^{18,23}$. More precisely, in the study of these outbreaks quoted above, in the areas of deforestation with recent human settlement, $\mathrm{Ny}$. whitmani and $\mathrm{Mg}$. migonei were found to be the most abundant species, without the presence of Lu. longipalpis ${ }^{6,23}$, showing the affinity of the LV agent vector with the urban environment.

Nyssomyia whitmani has been implicated in deforested areas as the vector responsible for the transmission of $\mathrm{CL}^{21,23}$. However, the species abundance observed in most households in urban environments, in view of the observations of FERNÁNDEZ et al. (2012) ${ }^{6}$ in areas of relatively low active transmission, leads us to conclude that there is little probability of transmission of the disease in our study area. The same may be true of Ev. cortelezzii which, although its natural infection with $L$. braziliensis has recently been demonstated ${ }^{15}$, might also, given its low abundance, have little probabilities of transmission in the area of study.

The National Leishmaniasis Program has made recommendations for several possible epidemic scenarios, including those with expanding colonization of vectors, moderate transmission of canine VL diseases, and intense transmission of human VL. Due to the fact that Puerto Iguazú is already considered to be at moderate risk at present, it is now necessary to intensify human and canine case control, as well as to take integrated prevention and control measures regarding the environment, vectors and reservoirs in the border area of the three countries involved.
In relation to vector control measures, it is important to consider the limited effectiveness of insecticides, which only cover a reduced-range focal spots and act for short periods ${ }^{16}$. Insecticides have no impact unless they are complemented with environmental management measures such as an increase in direct solar radiation on the soil, and a decrease in its humidity and organic matter, as well as the removal or rotation of pets or domestic animals coordinated with actions to control reservoirs. The results here presented justify our classification of Puerto Iguazú City as an area of potential VL transmission, especially as it is located on a frontier characterized by intense human transit (residents and tourists) as well as of dogs with VL. Furthermore, this risk scenario could extend to cover the entire region of the Argentina-Brazil-Paraguay border, which means that it would be advisable for the three countries involved to coordinate prevention and control measures in the region.

\section{RESUMO}

\section{Distribuição espacial de Phlebotominae em Puerto Iguazu, Misiones, área de fronteira da Argentina-Brasil-Paraguai}

O primeiro caso humano autóctone de leishmaniose visceral (LV) na Argentina ocorreu na cidade de Posadas (Misiones) em 2006, desde então, tem ocorrido um aumento na incidência e distribuição geográfica da doença. No período entre 2006 e 2012 foram detectados 107 casos humanos com 11 mortes. Em 2010 se constatou a presença de Lutzomyia longipalpis no município de Puerto Iguazú, localizado na fronteira entre Argentina-Brasil-Paraguai. O presente estudo teve como objetivo investigar a abundância e distribuição de Lu. longipalpis no município de Puerto Iguazú. Lu. longipalpis foi encontrada exclusivamente na área urbana, em $31 \%$ das amostras coletadas dos domicílios de referência $(\mathrm{n}=53), 67 \%$ das quais pertenciam às áreas de baixa abundância, $20 \%$ às de moderada e $13 \%$ às de alta abundância da espécie. Nyssomyia whitmani foi coletado em ambientes urbanos e periurbanos e Migonemyia migonei, somente nas periferias da cidade. Na atualidade, a cidade de Puerto Iguazú é considerada como de risco moderado; por isso, é necessário intensificar o controle tanto de casos humanos como de caninos e levar em conta as medidas de prevenção e controle do ambiente, dos vetores e dos reservatórios na zona de fronteira Argentina-Brasil-Paraguai.

\section{ACKNOWLEDGEMENTS}

We would like to thank the staff of the Institute for Tropical Medicine (INMeT) for their support and logistics and their interest in dealing with the problems of the region, and also to True English Institute for the language revision. We are also grateful to those residents of the city of Puerto Iguazú who opened their houses to us. This study was partially supported by OPS-TDR and by Fundación Mundo Sano.

\section{REFERENCES}

1. Cabrera AL. Fitogeografía de la República Argentina. Bol Soc Argent Bot. 1971;14:1-42.

2. Correa Antonialli SA, Torres TG, Paranhos Filho AC, Tolezano JE. Spatial analysis of American visceral leishmaniasis in Mato Grosso do Sul State, Central Brazil. J Infect. 2007;54:509-14.

3. De Carvalho MR, Valença, HF, Da Silva FJ, Pita-Pereira D, Araújo Pereira T, Britto C, et al. Natural Leishmania infantum infection in Migonemyia migonei (França, 1920) (Diptera: Psychodidae: Phlebotominae) the putative vector of visceral leishmaniasis in Pernambuco State, Brazil. Acta Trop. 2010;116:108-10. 
SANTINI, M.S.; GOULD, I.T.; ACOSTA, M.M.; BERROZPE, P.; ACARDI, S.A.; FERNÁNDEZ, M.S.; GÓMEZ, A. \& SALOMON, O.D. - Spatial distribution of Phlebotominae in Puerto Iguazú-Misiones, Argentina-Brazil-Paraguay border area. Rev. Inst. Med. Trop. Sao Paulo, 55(4): 239-43, 2013.

4. Feliciangeli MD, Delgado O, Suarez B, Bravo A. Leishmania and sand flies: proximity to woodland as a risk factor for infection in a rural focus of visceral leishmaniasis in west central Venezuela. Trop Med Int Health. 2006;11:1785-91.

5. Fernández MS, Salomón OD, Cavia R, Perez AA, Acardi SA, Guccione JD. Lutzomyia longipalpis spatial distribution and association with environmental variables in an urban focus of visceral leishmaniasis, Misiones, Argentina. Acta Trop. 2010;114:81-7.

6. Fernández MS, Lestani EA, Cavia R, Salomón OD. Phlebotominae fauna in a recen deforested area with American tegumentary leishmaniasis transmission (Puerto Iguazú, Misiones, Argentina): seasonal distribution in domestic and peridomestic environments. Acta Trop. 2012;122:16-23.

7. Galati EAB. Morfologia, terminologia de adultos e identificação dos táxons da América. In: Rangel EF, Lainson R. Flebotomíneos do Brasil. Rio de Janeiro: Fiocruz; 2003. p 53-175.

8. Gontijo CMF, Melo MNM. Leishmaniose visceral no Brasil: quadro atual, desafios e perspectivas. Rev Bras Epidemiol. 2004;7:338-49.

9. Gould IT, Pemer M, Santini MS, Saavedra SB, Bezzi G, Maglianese MI, et al. Leishmaniasis visceral en Argentina: análisis de la notificación y situación vectorial en las Provincias de Entre Ríos, Santa Fe, y Santiago del Estero, 2011. Medicina (B Aires). 2011;71:22-6.

10. INDEC. Instituto Nacional de Estadistica y Censos (Argentina). Censo Nacional de población, hogares y viviendas. 2010.

11. Lainson R, Rangel EF. Lutzomyia longipalpis and the eco-epidemiology of American visceral leishmaniasis, with particular reference to Brazil: a review. Mem Inst Oswaldo Cruz. 2005;100:811-27.

12. Oliveira DM, Saraiva EM, Ishikawa EA, de Sousa AA, da Silva EO, da Silva IM. Distribution of Phlebotominae fauna (Diptera: Psychodidae) across an urban-rural gradient in an area of endemic visceral leishmaniasis in northern Brazil. Mem Inst Oswaldo Cruz. 2011;106:1039-44.

13. PAHO. Update of American trypanosomiasis and leishmaniasis control and research: final report. Rio de Janeiro, 6-7 November 2007. Rio de Janeiro:PAHO/HDM/CD/512; 2008

14. Rangel EF, Lainson R. Proven and putative vectors of American cutaneous leishmaniasis in Brazil: aspects of their biology and vectorial competence. Mem Inst Oswaldo Cruz. 2009; 104:937-54.
15. Rosa J, Pereira DP, Brazil RP, Andrade Filho JD, Salomón O, Szelag E. Natural infection of Cortelezzii complex (Diptera: Psychodidae: Phlebotominae) with Leishmania braziliensis in Chaco, Argentina. Acta Trop. 2012;123:128-31.

16. Santini MS, Salomón OD, Acardi SA, Sandoval EA, Tartaglino LC. Lutzomyia longipalpis behavior and control at an urban visceral leishmaniasis focus in Argentina Rev Inst Med Trop Sao Paulo. 2010;52:187-91

17. Salomón OD, Orellano PW. Lutzomyia longipalpis in Clorinda, Formosa province, an area of potential visceral leishmaniasis transmission in Argentina. Mem Inst Oswaldo Cruz. 2005;100:475-6.

18. Salomón OD, Orellano PW, Quintana MG, Pérez S, Sosa Estani S, Acardi S, et al Transmisión de la leishmaniasis tegumentaria en la Argentina. Medicina (B Aires). 2006;66:211-9.

19. Salomón OD, Quintana MG, Rosa JR. Ecoepidemiología de la leishmaniasis cutánea en Argentina. Salud Ciencia. 2008;16:514-20.

20. Salomón O, Sinagra A, Nevot M, Barberian G, Paulin P, Estevez J, et al. First visceral leishmaniasis focus in Argentina. Mem Inst Oswaldo Cruz. 2008:103:109-11.

21. Salomón OD, Acardi SA, Liotta DJ, Fernández MS, Lestani E, López D, et al. Epidemiological aspects of cutaneous leishmaniasis in the Iguazú falls area of Argentina. Acta Trop. 2009;109:5-11

22. Salomón OD, Quintana MG, Bezzi G, Morán Ml, Betbeder E, Valdéz DV. Lutzomyia migonei as putative vector of visceral leishmaniasis in la Banda, Argentina. Acta Trop. 2010;113:84-7

23. Salomón OD, Fernández MS, Santini MS, Saavedra S, Montiel N, Ramos M, et al. Distribución de Lutzomyia longipalpis en la Mesopotamia Argentina, 2010. Medicina (B Aires). 2011;71:22-6

24. Salomón OD, Basmajdian Y, Fernández MS, Santini MS. Lutzomyia longipalpis in Uruguay: the first report and the potential of visceral leishmaniasis transmission Mem Inst Oswaldo Cruz. 2011;106:381-2.

25. Woolhouse ME, Dye C, Etard JF, Smith T, Charlwood JD, Garnett GP, et al Heterogeneities in the transmission of infectious agents: implications for the design of control programs. Proc Natl Acad Sci USA. 1997;94,338-42.

26. World Health Organization. Intensified control of neglected diseases: report of an international workshop. WHO/CDS/CPE/CEE/2004.5. Geneva: WHO, 2004.

Received: 17 July 2012

Accepted: 3 January 2013 